\title{
Efficacy and Safety of Flow-Diverter Therapy for Recurrent Aneurysms after Stent-Assisted Coiling
}

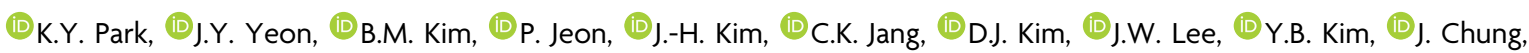 \\ (D)D.H. Song, 1 H.G. Park, and $\mathbb{1}^{\text {J.S. Park }}$
}

\begin{abstract}
BACKGROUND AND PURPOSE: Flow-diverter treatment for previously stented aneurysms has been reported to be less effective and prone to complications. In this study, we evaluated the effectiveness and safety of flow diverters for recurrent aneurysms after stent-assisted coiling.
\end{abstract}

MATERIALS AND METHODS: Patients who underwent flow-diverter placement for recurrent aneurysms after stent-assisted coiling between March 2015 and March 2019 were recruited. Clinical and radiographic characteristics and clinical and angiographic outcomes were retrospectively evaluated.

RESULTS: Among 133 patients who underwent flow-diverter insertion, 17 (male/female ratio = 5:12; mean age, 53.8 years) were treated for recurrent aneurysms after stent placement with $(n=16)$ or without $(n=1)$ coiling. Eight patients initially presented with subarachnoid hemorrhage; 7, with headache; and 2, with visual field defects. Angiographic morphology included large/giant saccular in 12 patients, dissecting in 2, fusiform in 1, traumatic pseudoaneurysm in 1, and ruptured blood blister-like aneurysm in 1. The duration between the first treatment and flow-diverter placement ranged from 2 weeks to 15 months (median, 6 months). Flow-diverter placement was successful in all cases without any complications. All patients had favorable outcomes (mRS, 0-2), without any newly appearing symptoms. Aneurysms were followed up with conventional angiography at least once in 6-18 months. Sixteen aneurysms showed complete occlusion, and 1 aneurysm was enlarged.

CONCLUSIONS: Results from this case series investigating flow-diverter placement for recurrent aneurysms after stent-assisted coiling suggested that the procedure is safe and effective. Further study in a larger population may be warranted.

ABBREVIATIONS: LVIS = low-profile visualized intraluminal support; PED = Pipeline Embolization Device; SAC = stent-assisted coiling

$E^{\mathrm{n}}$ ndovascular coil embolization is a standard treatment for intracranial aneurysms. However, its durability and potential for angiographic recurrence are still major shortcomings. ${ }^{1,2}$ Although stent placement with coiling can help enhance durability, the recurrence rate is reported to be approximately up to $14.9 \%$, even after

Received October 11, 2019; accepted after revision January 27, 2020.

From the Department of Neurosurgery (K.Y.P., C.K.J., J.W.L., Y.B.K., J.C.), Yonsei University College of Medicine, Seoul, Republic of Korea; Department of Neurosurgery (J.Y.Y.), Sungkyunkwan University School of Medicine, Seoul, Republic of Korea; Department of Radiology (B.M.K., J.-H.K., D.J.K., D.H.S., H.G.P., J.S.P.), Severance Stroke Center, Severance Hospital, Yonsei University College of Medicine, Seoul, Republic of Korea; and Department of Radiology (P.J.), Samsung Medical Center, Sungkyunkwan University School of Medicine, Seoul, Republic of Korea.

K.Y. Park and J.Y. Yeon contributed equally.

Please address correspondence to Byung Moon Kim, MD, PhD, Interventional Neuroradiology, Severance Stroke Center, Department of Radiology, Yonsei University College of Medicine, Severance Hospital, 50-1, Yonsei-ro, Seodaemun-gu, Seoul, Republic of Korea; e-mail: bmoon21@hanmail.net; bmoon21@yuhs.ac

Indicates article with supplemental on-line table.

http://dx.doi.org/10.3174/ajnr.A6476 successful stent-assisted coiling (SAC). ${ }^{3}$ Conversely, retreatment of previously stented aneurysms is challenging for both neurosurgeons and neurointerventionalists due to its questionable efficacy and safety. ${ }^{4,5}$ Thus, neither conventional clipping nor coiling has provided reasonable outcomes as a retreatment technique for recurrent aneurysms after SAC.

Following the introduction of the early version of the Pipeline Embolization Device (PED; Medtronic, Minneapolis, Minnesota), ${ }^{6,7}$ flow diverters have gained increasing acceptance for aneurysm treatment. In particular, these were useful for the treatment of complex and complicated aneurysms, such as large or giant, dissecting, and blood blister-like aneurysms. Additionally, these types of aneurysms were also susceptible to recurrence. ${ }^{8-11}$ Thus, flow diverters may be an alternative treatment option for recurrent aneurysms after SAC. Unfortunately, previous studies on flow-diverter treatment for previously stented aneurysms reported some technical issues and unfavorable results. ${ }^{12-16}$ Nelson et $\mathrm{al}^{12}$ reported that 1 in 4 aneurysms previously treated with another stent was not occluded at 
180 days after PED placement. Fischer et $\mathrm{al}^{13}$ reported that the adverse event rate was $13 \%$, and the successful occlusion rate was $65 \%$ in 30 cases of PED for recurrent aneurysms after SAC. Daou et $\mathrm{al}^{15}$ reported that the complete occlusion rate was $55.6 \%$, with a $14.3 \%$ complication rate in PEDs after SAC. However, recent neurointerventional techniques and devices may be helpful in overcoming these technical issues, and more acceptable outcomes are expected.

In the present study, we report on the effectiveness and safety of flow-diverter treatment for recurrent aneurysms after SAC.

\section{MATERIALS AND METHODS}

The institutional review board of each hospital approved this study and waived the requirement for patient informed consent due to its retrospective design. After the introduction of the PED, patients who underwent flow-diverter placement for the treatment of recurrent aneurysms after SAC in 5 hospitals between March 2015 and March 2019 were recruited.

Planning of flow-diverter treatment was based on consensus by a multidisciplinary team meeting after the careful evaluation of $3 \mathrm{D}$ angiograms. Flow-diverter placement was chosen as a retreatment method after agreement that the initial aneurysm was large/giant, ruptured dissecting, or blood blister-like. On the basis of previous results, those types of aneurysms were thought to be prone to re-recurrence, even if retreatment was successful with additional coil insertion.

In cases in which dual-antiplatelet medication was stopped or changed to aspirin monotherapy before the PED retreatment procedure, dual-antiplatelet medication (aspirin, $100 \mathrm{mg}$, and clopidogrel, $75 \mathrm{mg}$ ) was resumed for at least 5 days. Because no patient showed resistance on the antiplatelet resistance test at the initial SAC and no patient had thromboembolic events during follow-up, an additional antiplatelet resistance test before PED placement was not routinely performed. After the completion of treatment, the dual-antiplatelet medication was maintained for at least 6 months, and subsequently, the regimen was changed to aspirin monotherapy, which was continued indefinitely.

All clinical and radiologic data were obtained from the electronic medical records and a prospectively registered aneurysm data base. Data were retrospectively reviewed.

\section{Flow-Diverter Placement}

All procedures were conducted with the patient under general anesthesia. A 5F intermediate catheter was used in all except 3 cases, combined with a $6 \mathrm{~F}$ or $7 \mathrm{~F}$ Shuttle guide sheath (Cook, Bloomington, Indiana) or a $6 \mathrm{~F}$ Neuron MAX (Penumbra, Alameda, California). The routine procedural details were as follows: 1) After the placement of a $5 \mathrm{~F}$ intermediate catheter (Sofia; MicroVention, Aliso Viejo, California; Navien, Medtronic, Minneapolis, Minnesota; Revive, Codman Neurovascular, Raynham, Massachusetts) within a $6 \mathrm{~F}$ or $7 \mathrm{~F}$ Shuttle or a $6 \mathrm{~F}$ Neuron MAX catheter, the Marksman catheter (Medtronic) was introduced and advanced over a 0.014 -inch guidewire into 1 branch of the parent artery beyond the stented segment; 2) the intermediate catheter was advanced over the Marksman catheter and microwire as far as possible beyond the stented segment of the parent artery; 3) the size-matched flow diverter was introduced and placed to span the entire stented segment; if required, multiple flow diverters were used to span the entire stented segment; and 4) if an immediate postimplantation angiogram or flat panel CT image showed equivocal apposition of the flow diverter and a previously placed stent in the segment where a metallic artifact due to the coil mass was not prominent, or if the apposition between the PED and the preplaced stent could not be assessed due to the surrounding coil mass (Fig 1), balloon angioplasty was performed for better apposition between the preplaced stent and the flow diverter.

\section{Clinical and Angiographic Follow-Up}

Routine clinical follow-up was performed at 1, 3, 6, and 18 months. Routine angiographic follow-up was performed at 6 months. If the 6-month angiogram did not show complete occlusion of the aneurysm, further follow-up angiographies were scheduled at 12 months and 18-24 months.

\section{Outcome Measurements}

Procedural success was defined as the full expansion of the flow diverter spanning the entire stented segment of the parent artery.

Clinical outcomes were assessed with the mRS at the latest clinical follow-up. Treatment-related morbidity was defined as the development of any new deficit due to treatment-related complications that were still present at discharge. Treatmentrelated mortality was defined as death of the patient from treatment-related complications during admission or clinical followup. In addition, any treatment-related complication other than neurologic complication was evaluated. Follow-up angiographic outcomes were assessed according to the Raymond class, in which class 1 is defined as complete occlusion; class 2, as neck remnant; and class 3 , as sac remnant. ${ }^{17}$

The procedural success rate, treatment-related morbidity and mortality, and clinical and angiographic follow-up outcomes were retrospectively assessed.

\section{Statistical Analysis}

Because this study included the results of a single arm of flowdiverter insertion for recurrent aneurysms after SAC, without comparison with other types of treatment, only descriptive statistics are presented. All data are presented as mean and range for continuous variables and number and percentage for categoric variables.

\section{RESULTS}

Among 133 patients who underwent flow-diverter insertion, 17 (male/female ratio $=5: 12$; mean age, 53.8 years $)$ were treated for recurrent aneurysms after stent placement with $(n=16)$ or without $(n=1)$ coiling. Baseline characteristics of patients and aneurysms and follow-up clinical and angiographic outcomes are shown in the On-line Table.

Eight patients initially presented with subarachnoid hemorrhage; 7, with headache; and 2, with a visual field defect. Except for 1 patient (case 7, Fig 1) who presented with a ruptured ICA fusiform aneurysm and had end-stage renal disease, no patient had an underlying comorbidity. The aneurysm types included large/giant saccular in 12 patients, dissecting in 2, fusiform in 1 

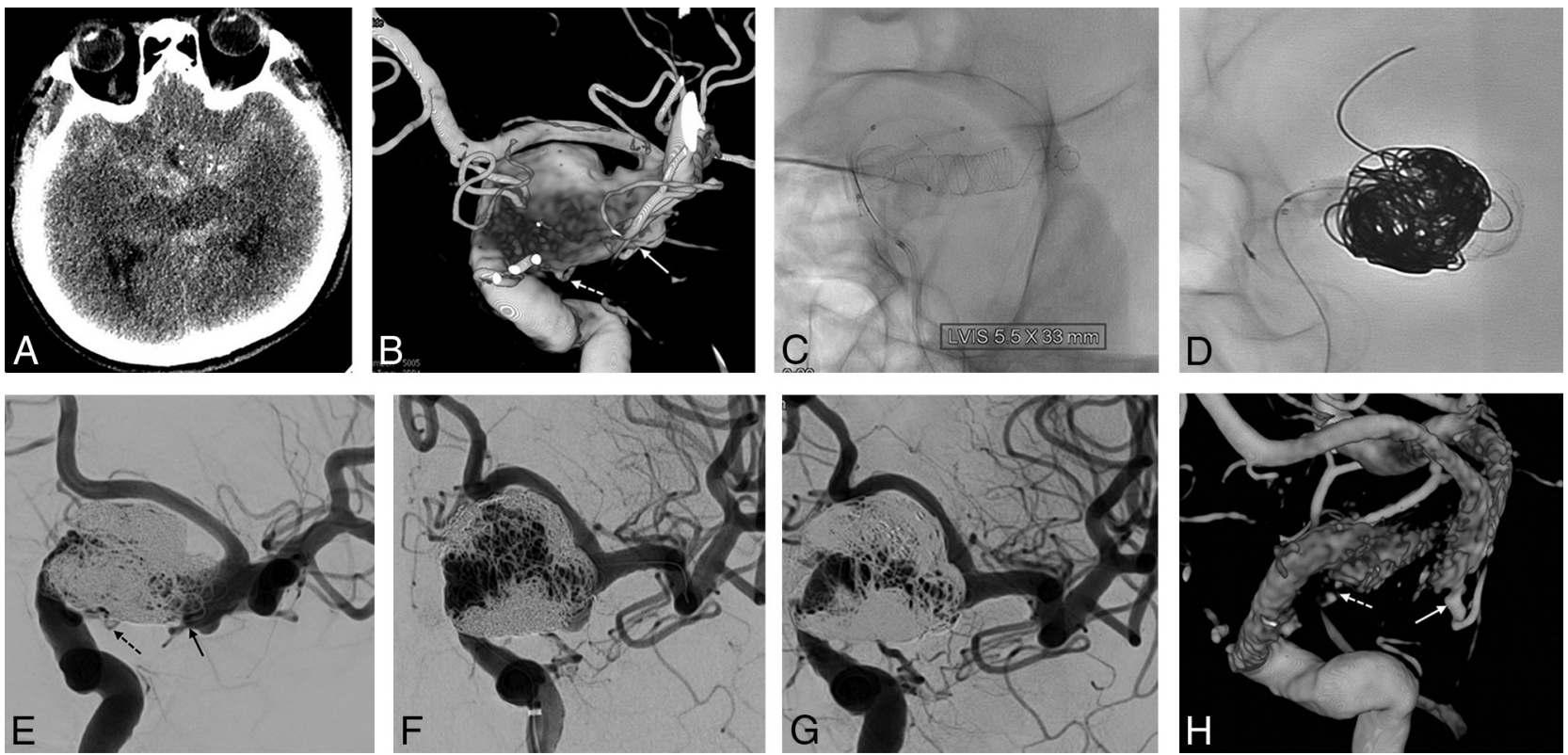

FIG 1. A 54-year-old man with subarachnoid hemorrhage. A, A nonenhanced CT image shows a diffuse subarachnoid hemorrhage in the basal cistern. B, A 3D volume-reconstruction image shows a fusiform aneurysm of the left distal ICA. Both the anterior choroidal (solid arrow) and posterior communicating (dashed arrow) arteries arise from the fusiform aneurysm. C, Three LVIS Blue devices are deployed in a telescopic manner from the ICA cavernous segment to the middle cerebral artery M1 segment. D, Coil embolization performed using the balloon-in-stent technique. E, Immediate postembolization shows near-complete embolization. Both the anterior choroidal (solid arrow) and posterior communicating (dashed arrow) arteries are saved. F, One-year follow-up angiogram shows a major recurrence. Note that the left anterior cerebral artery is tented due to the mass effect of the fusiform aneurysm. G, One-year follow-up angiogram after Pipeline Embolization Device implantation shows complete occlusion. $H$, Subtracted 3D reconstruction image shows a well-remodeled ICA with both anterior choroidal (solid arrow) and posterior communicating (dashed arrow) arteries saved.

(Fig 1), traumatic pseudoaneurysm in 1, and blood blister-like in 1 ; and the aneurysm locations were the ICA intradural segment in 13 patients, ICA cavernous segment in 1, MCA in 2, and anterior communicating artery in 1 (Fig 2). The types of stents initially used were the Enterprise (Codman Neurovascular) in 11 patients and the Low-Profile Visualized Intraluminal Support (LVIS; MicroVention), Blue, or Jr in 6. Flow-diverter placement was successful in all patients. At retreatment, the mRS was 0 in nine, 1 in four, 2 in 2 , and 3 in 2 patients, respectively. The duration between the first treatment and flow-diverter placement ranged from 2 weeks to 15 months (median, 6 months). One patient was retreated 2 weeks after initial treatment. The patient (case 17) had a ruptured blood blister-like aneurysm and showed aneurysm enlargement from 3.5 to $5 \mathrm{~mm}$ at 2 weeks' follow-up angiography after overlapping of 3 LVIS stents as the initial treatment. Due to fear of rehemorrhage, the patient was urgently retreated with 2 PEDs.

A single PED was used in 14; two PEDs, in 2; and 3 PEDs, in 1 patient. Of a total of 21 PEDs, PED Classic and PED Flex were used in 7 and 14, respectively. In every case, the previously stented segment was completely covered by the PED. Balloon angioplasty was performed because incomplete expansion or poor apposition of the PED was suspected in 4 cases, and the apposition between the PED and the preplaced stent could not be assessed due to a surrounding coil mass in the fusiform aneurysm (case 7, Fig 1). There was no difference in the frequency of balloon angioplasty between PED Classic ( 2 of 7 patients, 28.6\%) and PED Flex (3 of 10 patients, 30\%). There were no periprocedural neurologic or other complications including vascular injury, access site complication, and contrast material-induced kidney injury.

At the most recent follow-up (mean, 22 months; range, 6-48 months), all patients had favorable outcomes (mRS, $0-2$ ), without any newly appearing neurologic deficits. All aneurysms were followed up with conventional angiography at least once, 618 months after PED placement. Sixteen aneurysms (94.1\%) showed complete occlusion; however, 1 initially ruptured dissecting MCA aneurysm (case 15) was enlarged. This enlarged dissecting aneurysm underwent a third treatment using an additional flow-diverter placement and has not yet undergone follow-up angiography. Asymptomatic in-stent stenosis $(>50 \%)$ was observed in 1 case on follow-up angiography.

\section{DISCUSSION}

In this case series, all aneurysms were successfully retreated using the PED without any complications. Furthermore, although the initial aneurysms (large-/giant-sized, ruptured dissecting, or blood blister-like) were prone to re-recurrence even after successful retreatment with additional coil insertion, $94.1 \%$ of the aneurysms retreated using flow diverters had complete occlusion on follow-up angiography.

During the coiling procedure for an intracranial aneurysm, a stent may be used for multiple purposes, such as preservation of a parent or branch artery, prevention of microcatheter kickback, and increased durability. Despite these advantages, SAC has not been widespread until recently due to its technical difficulty and possible complications. However, with the recent development of 

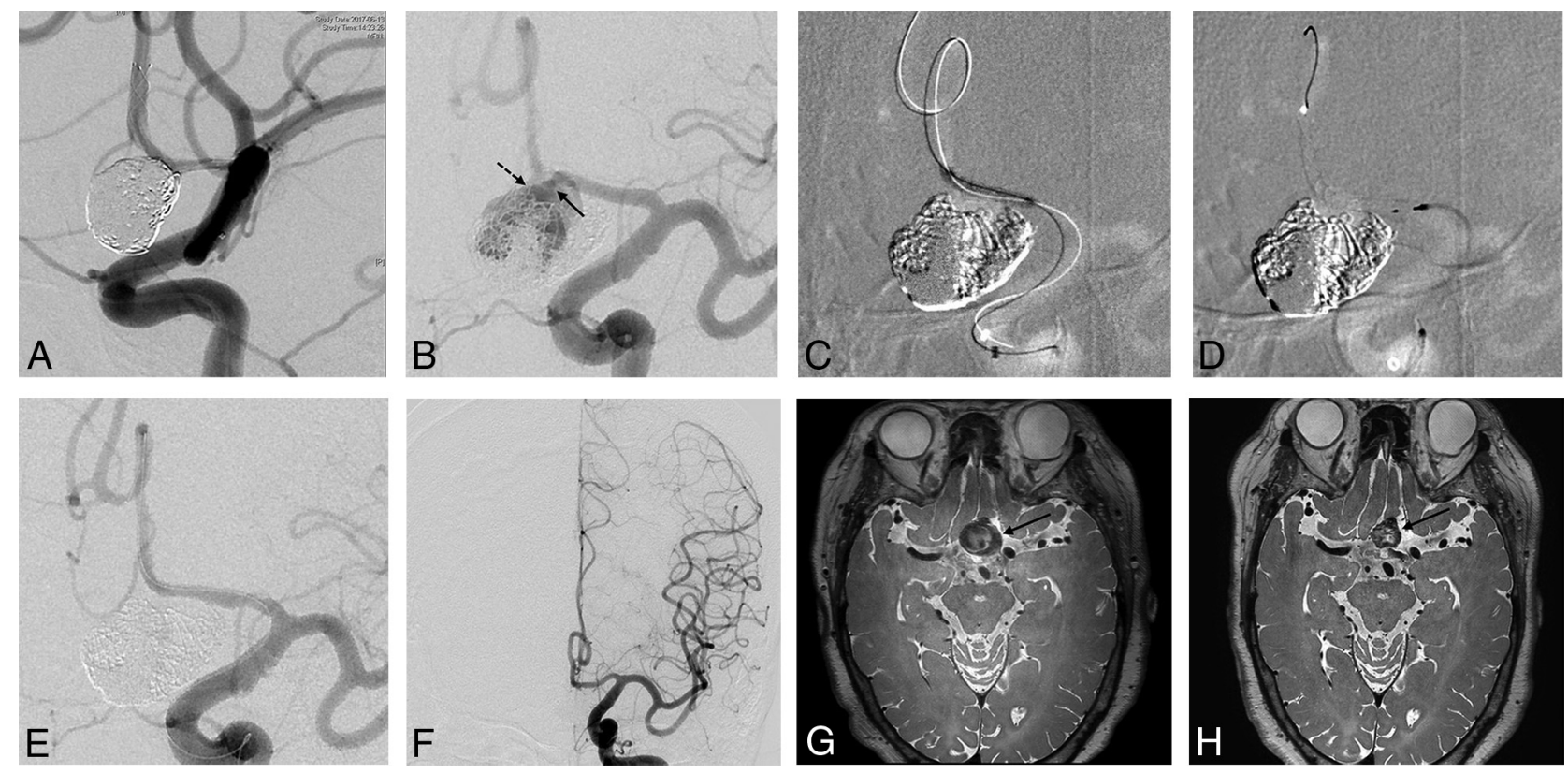

FIG 2. A 67-year-old woman with a partially thrombosed giant aneurysm at the anterior communicating artery. A, Angiogram immediately after LVIS Jr-assisted coiling shows complete occlusion of the aneurysm sac. B. The 14-month follow-up angiogram shows a major recurrence with occlusion of the stent. The left anterior cerebral artery A2 segment is supplied through the recurrent aneurysm sac. Note blood flow from the $\mathrm{A} 1$ segment through the aneurysm sac to the $\mathrm{A} 2$ segment. The solid arrow indicates the inflow from A1 into the aneurysm sac, and the dashed arrow indicates the outflow from the aneurysm sac to A2. C. The A2 segment is navigated through the inside of the stent using a 0.0165 -inch microcatheter and a 0.014-inch microwire. Next, balloon angioplasty is performed to open the occluded stented segment of the anterior cerebral artery using a Gateway balloon (Stryker, Kalamazoo, Michigan). D, The Pipeline Flex is deployed spanning the entire stented segment. E, An angiogram immediately after PED implantation shows complete occlusion of the recurrent aneurysm. $F$, The 10-month follow-up angiogram shows complete occlusion of the aneurysm. MR image before PED implantation $(G)$ and at 10-month follow-up $(H)$ show the decreased size of the thrombosed giant aneurysm (solid arrow).

low-profile stents, SAC may be an easier and safer procedure than those using previous stents. ${ }^{18-20}$ Currently, SAC has become more common and is used in up to $32.7 \%$ of all endovascular coiling. ${ }^{21}$ However, because a recurrence after SAC is not uncommon, management after recurrence is an important clinical issue that remains controversial.

Surgical retreatment for previously stented aneurysms is challenging and complicated because direct manipulation of the stented artery or extrusion of the previous coil mass is required, which is associated with a risk of thromboembolism and arterial tearing. Thus, endovascular coil addition with or without a stent has been widely accepted as a retreatment technique for recurrent aneurysms after SAC. ${ }^{22,23}$ However, this conventional endovascular retreatment cannot fully overcome the risk of repeat recurrences because most target aneurysms in this study were vulnerable to recurrence by nature.

Flow diverters are a new treatment strategy for intracranial aneurysms. The flow diverter gradually occludes an aneurysm within an organized thrombus by enhancing an intra-aneurysmal flow diversion ${ }^{24}$ and neointima formation. ${ }^{25}$ Consequently, flowdiverter treatment has a lower probability of recurrence than conventional coiling, even in lesions vulnerable to recurrence. Therefore, a flow diverter might be a better treatment option for recurrent aneurysms even after SAC. However, in previous studies, flow-diverter treatment after stent placement was reportedly less effective and more complicated, with $40.9 \%-75.0 \%$ occlusion rates and a higher complication rate, up to $16.7 \%{ }^{12-16}$
These unfavorable results may stem from several technical issues regarding flow-diverter deployment within a previously placed stent. First, the microwire may go through the strut of a previous stent and potentially traverse in an "in-out-in" fashion. This phenomenon results in incomplete opening of the flow diverter. However, in most cases in the present study, this drawback was overcome by advancing the $5 \mathrm{~F}$ intermediate catheter distally over the Marksman catheter, which promised the inner lumen and the central axis of the previous stent. This method ensures that the intermediate catheter cannot traverse the previous stent in the "inout-in" fashion, though the microwire and microcatheter may. ${ }^{26}$ Second, the previously placed stent strut or coil interrupts the visibility of the flow diverter, and the entire process of flow-diverter deployment cannot be easily identified using fluoroscopy. Thus, incomplete expansion of the flow diverter may potentially occur despite using a size-matched flow diverter and may be a main cause of thromboembolic complications and less effective flow diversion. In the present study, when a postimplantation angiogram or flat panel CT image showed equivocal apposition of the flow diverter in the segment where a metallic artifact due to coil mass was not prominent or when the wall apposition of the PED could not be assessed due to the surrounding coil mass, balloon angioplasty was performed. Balloon angioplasty was helpful for better apposition of the flow diverter to the previous stent. ${ }^{27}$ Third, during the deployment of the flow diverter within the previously stented artery, the usual drag-and-drop technique can cause anchoring of the flow diverter to the previous stent, followed by a stretch of the flow 
diverter. Therefore, instead of the drag-and-drop technique, direct deployment of the flow diverter to its final location may be helpful for the retreatment of stented aneurysms. ${ }^{14,28}$

Finally, if the previous stent did not sufficiently appose the vessel wall, blood flow may occur between the stent and vessel wall, referred to as an endoleak. The risk of endoleak is greater in cases with a previous stent than in those with a previous flow diverter ${ }^{28}$ and may become an obstacle to flow diversion and neointima formation. Therefore, careful review and selection of patients are mandatory before using flow-diverter treatment for recurrent aneurysms after SAC. In addition, the flow diverter should be deployed to span the entire length of the previously placed stent, and both proximal and distal ends of the flow diverter should contact the normal parent artery, without interposition of the previous stent struts. Although an unrecognized gap may exist between the parent artery and the previously placed stent, the gap could be a semi-closed space and gradually obliterated if the flow diverter fully covered the entire length of the stent.

The present study demonstrated better clinical and angiographic outcomes compared with those of previous studies. This improved outcome may be largely due to rapid development of neurointerventional devices, including a new generation of PED (PED Flex), and intermediate catheters. In addition, the operators' gaining more experience in PED placement may also partly contribute to the improved results.

In the present study, a selection bias existed due to the retrospective design. The treatment strategy for every patient was determined after in-depth discussion among vascular neurosurgeons and interventional neuroradiologists for better clinical and anatomic outcomes. However, the present study was focused on demonstrating that flow-diverter treatment can be a retreatment option for specific situations such as SAC instead of the standard treatment (coil addition). Another limitation was the relatively small case series with a short-term follow-up. However, once complete occlusion of the aneurysm was achieved with the flow diverter, recurrence was extremely rare; therefore, long-term follow-up did not appear necessary. Further studies with larger populations are warranted to determine cases that are appropriate for flow-diverter treatment for recurrences after SAC.

\section{CONCLUSIONS}

In this case series, flow-diverter treatment for recurrent aneurysms after SAC was demonstrated to be safe and effective. Further study in a larger population is warranted.

\section{ACKNOWLEDGMENTS}

We would like to thank Editage (www.editage.co.kr) for English language editing.

Disclosures: Dong Joon Kim-UNRELATED: Travel/Accommodations/Meeting Expenses Unrelated to Activities Listed: Stryker Pacific Limited.

\section{REFERENCES}

1. Raymond J, Guilbert F, Weill A, et al. Long-term angiographic recurrences after selective endovascular treatment of aneurysms with detachable coils. Stroke 2003;34:1398-403 CrossRef Medline
2. Molyneux AJ, Birks J, Clarke A, et al. The durability of endovascular coiling versus neurosurgical clipping of ruptured cerebral aneurysms: 18-year follow-up of the UK cohort of the International Subarachnoid Aneurysm Trial (ISAT). Lancet 2015;385:691-97 CrossRef Medline

3. Piotin M, Blanc R, Spelle L, et al. Stent-assisted coiling of intracranial aneurysms: clinical and angiographic results in 216 consecutive aneurysms. Stroke 2010;41:110-15 CrossRef Medline

4. Liu JJ, Nielsen TH, Abhinav K, et al. Surgical treatment of recurrent previously coiled and/or stent-coiled intracerebral aneurysms: a single-center experience in a series of 75 patients. World Neurosurg 2019 Jan 11. [Epub ahead of print] CrossRef Medline

5. Muskens IS, Hertgers O, Lycklama À Nijeholt GJ, et al. Outcomes of retreatment for intracranial aneurysms: a meta-analysis. Neurosurgery 2019;85:750-61 CrossRef Medline

6. Kallmes DF, Ding YH, Dai D, et al. A new endoluminal, flow-disrupting device for treatment of saccular aneurysms. Stroke 2007;38:2346-52 CrossRef Medline

7. Fiorella D, Woo $\mathrm{HH}$, Albuquerque FC, et al. Definitive reconstruction of circumferential, fusiform intracranial aneurysms with the Pipeline Embolization Device. Neurosurgery 2008;62:1115-20 CrossRef Medline

8. Kim BM, Shin YS, Baik MW, et al. Pipeline Embolization Device for large/giant or fusiform aneurysms: an initial multi-center experience in Korea. Neurointervention 2016;11:10-17 CrossRef Medline

9. Oishi H, Teranishi K, Yatomi K, et al. Flow diverter therapy using a Pipeline Embolization Device for 100 unruptured large and giant internal carotid artery aneurysms in a single center in a Japanese population. Neurol Med Chir (Tokyo) 2018;58:461-67 CrossRef Medline

10. Fang YB, Lin A, Kostynskyy A, et al. Endovascular treatment of intracranial vertebrobasilar artery dissecting aneurysms: parent artery occlusion versus flow diverter. Eur J Radiol 2018;99:68-75 CrossRef Medline

11. Zhu D, Yan Y, Zhao P, et al. Safety and efficacy of flow diverter treatment for blood blister-like aneurysm: a systematic review and meta-analysis. World Neurosurg 2018;118:e79-86 CrossRef Medline

12. Nelson PK, Lylyk P, Szikora I, et al. The Pipeline Embolization Device for the Intracranial Treatment of Aneurysms trial. AJNR Am J Neuroradiol 2011;32:34-40 CrossRef Medline

13. Fischer S, Vajda Z, Aguilar Perez M, et al. Pipeline Embolization Device (PED) for neurovascular reconstruction: initial experience in the treatment of 101 intracranial aneurysms and dissections. Neuroradiology 2012;54:369-82 CrossRef Medline

14. Chalouhi N, Chitale R, Starke RM, et al. Treatment of recurrent intracranial aneurysms with the Pipeline Embolization Device. J Neurointerv Surg 2014;6:19-23 CrossRef Medline

15. Daou B, Starke RM, Chalouhi N, et al. Pipeline Embolization Device in the treatment of recurrent previously stented cerebral aneurysms. AJNR Am J Neuroradiol 2016;37:849-55 CrossRef Medline

16. Heiferman DM, Billingsley JT, Kasliwal MK, et al. Use of flow-diverting stents as salvage treatment following failed stent-assisted embolization of intracranial aneurysms. J Neurointerv Surg 2016;8:692-95 CrossRef Medline

17. Roy D, Milot G, Raymond J. Endovascular treatment of unruptured aneurysms. Stroke 2001;32:1998-2004 CrossRef Medline

18. Shankar JJ, Quateen A, Weill A, et al. Canadian Registry of LVIS Jr for Treatment of Intracranial Aneurysms (CaRLA). J Neurointerv Surg 2017;9:849-53 CrossRef Medline

19. Park KY, Kim BM, Kim DJ, et al. Y-configuration stenting for coiling of wide-neck bifurcation aneurysms using Low-profile Visualized Intraluminal Support Junior. J Neurointerv Surg 2019;11:400-04 CrossRef Medline

20. Caragliano AA, Papa R, Pitrone A, et al. The low-profile Neuroform Atlas stent in the treatment of wide-necked intracranial aneurysms: immediate and midterm results-an Italian multicenter registry. J Neuroradiol. 2019 Apr 2. [Epub ahead of print]

21. Turk AS, Johnston SC, Hetts S, et al. Geographic differences in endovascular treatment and retreatment of cerebral aneurysms. AJNR Am J Neuroradiol 2016;37:2055-59 CrossRef Medline 
22. Hauck EF, Natarajan SK, Hopkins LN, et al. Salvage Neuroform stent-assisted coiling for recurrent giant aneurysm after wafflecone treatment. J Neurointerv Surg 2011;3:27-79 CrossRef Medline

23. Song Y, Wang Y, Li C, et al. Retreatment and outcomes of recurrent intracranial vertebral artery dissecting aneurysms after stent assisted coiling: a single center experience. PLoS One 2014;9:e113027 CrossRef Medline

24. Narata AP, de Moura FS, Larrabide I, et al. The role of hemodynamics in intracranial bifurcation arteries after aneurysm treatment with flow-diverter stents. AJNR Am J Neuroradiol 2018;39:323-30 CrossRef Medline

25. Lee JY, Cho YD, Kang HS, et al. Healing of aneurysm after treatment using flow diverter stent: histopathological study in experimental canine carotid side wall aneurysm. J Korean Neurosurg Soc 2020;63:34-44 CrossRef Medline

26. Mascitelli JR, Wei D, Oxley TJ, et al. A technical consideration when using flow diversion for recurrent aneurysms following stent-assisted coiling. J Neurointerv Surg 2017;9:e24 CrossRef Medline

27. Kühn AL, Rodrigues KM, Wakhloo AK, et al. Endovascular techniques for achievement of better flow diverter wall apposition. Interv Neuroradiol 2019;25:344-47 CrossRef Medline

28. Bender MT, Vo CD, Jiang B, et al. Pipeline embolization for salvage treatment of previously stented residual and recurrent cerebral aneurysms. Interv Neurol 2018;7:359-69 CrossRef Medline 